\title{
Poder local, regional e redes políticas da família Anibelli, no Paraná
} (1944-2017)

\author{
Juliano Gustavo Zimmer ${ }^{1}$
}

Alessandro Cavassin Alves 2

\begin{abstract}
RESUMO: O artigo a seguir tem por finalidade analisar sociologicamente três atores políticos da família Annibelli envolvidos no poder regional paranaense no período que vai de 1944 a 2017, presentes em Prefeitura, Secretarias de Estado, Assembleia Legislativa, Ministério Público e Governo, dessa forma construindo redes políticas. A pesquisa irá identificar a trajetória de vida de cada um deles, do ponto de vista geracional, do poder sendo passado de pai para filho e neto. A intenção é destacar as heranças familiares, associadas ao poder econômico da família em questão e partindo da hipótese de que os candidatos com maior potencial eleitoral pertencem a famílias históricas, pelo fato de Ihes proporcionar vantagens sob os demais concorrentes. Ricardo Costa de Oliveira destaca a importância de se "mapear" as famílias e suas conexões políticas que acabam se perpetuando no poder, até para se compreender melhor a dinâmica eleitoral, tornando-se fonte de informação para a sociedade.
\end{abstract}

Palavras-chave: Família Annibelli. Poder regional. Redes políticas.

\section{Local, regional and political power of the Anibelli family in Paraná (1944-2017)}

\begin{abstract}
The following article aims to analyze sociologically three political actors of the Annibelli family involved in the regional power of Paraná in the period from 1944 to 2017, present in City Hall, Secretaries of State, Legislative Assembly, Public Ministry and Government, thus building political networks. The research will identify the life trajectory of each of them, from the generational point of view, of the power being passed from father to son and grandson. The intention is to highlight family inheritances, associated with the economic power of the family in question and based on the hypothesis that candidates with greater electoral potential belong to historical families, because it gives them advantages over other competitors. Ricardo Costa de Oliveira highlights the importance of "mapping" families and their political connections that end up perpetuating power, even to better understand the electoral dynamics, becoming a source of information for society.
\end{abstract}

Keywords: Family Annibelli. Regional power. Political networks.

- Enviado em 01/05/2017

- Aprovado em 17/05/2017

1 Comunicação Social, Jornalismo. Uma versão preliminar desse texto foi apresentada no VIII Seminário Nacional de Sociologia e Política realizado de 17 a 19 de maio de 2017 na UFPR. E-mail: juguzi@hotmail.com

2 Ciências Sociais, Doutor em Sociologia, Professor. Uma versão preliminar desse texto foi apresentada no VII Seminário Nacional de Sociologia e Política realizado de 17 a 19 de maio de 2017 na UFPR. E-mail alessandrocavassin@gmail.com 


\section{INTRODUÇÃO}

A família Annibelli tem uma história política interessante, iniciando com Antônio Annibelli como prefeito, depois, deputado estadual, passando o cargo para o filho, e atualmente o mesmo cargo eletivo está com o neto, ou seja, um poder político que começou em 1944 e perdura até os dias atuais, passando por três gerações, que somam 72 anos ocupando a cadeira de deputado estadual na Assembleia Legislativa do Paraná. Como entender tal dinâmica democrática?

Mas, ampliando o tempo de mando, é possível identificar a conexão da família Annibelli com a família Lustosa.

O sogro de Antônio Annibelli era Manoel Lustosa Martins (Clevelândia, 1892-1983) que descendia de portugueses e que remonta quatro famílias que se tornaram tracionais no Paraná, por solicitarem sesmarias já no século XVII: Balthazar Carrasco dos Reis, Matheus Martins Leme, Bernardo Martins Ferreira e Felipe Ferreira de Magalhães. São pioneiros, não só fundadores e povoadores de Curitiba como primeiros desbravadores do planalto paranaense (MARTINS, 1992, p.79). O avô de Manuel Lustosa, Bento dos Santos Martins, casado com Dona Anna Pereira da Luz, que era neta de Francisco Pereira Magalhães, grande proprietário de terras na região da Serra do Mar, ou seja, grande fazendeiro da região acumulando oito mil alqueires de terra (Idem).

Além de terras, Francisco Pereira Magalhães era ainda proprietário de Engenho de ervamate em Morretes. $\mathrm{O}$ avô Bento tinha registro de terras nos municípios de São José dos Pinhais e da Lapa. Os ascendentes de Manoel Lustosa Martins penetraram, posteriormente, nos Campos de Guarapuava, entre elas a bandeira de Joaquim Ferreira dos Santos. Já Manoel continuou como desbravador da região Sudoeste paranaense. E, seguindo a tradição familiar, "Manoel Lustosa Martins foi proprietário de aproximadamente dez mil alqueires de terras entre as regiões Sudoeste de Paraná e Oeste de Santa Catarina" (Ibidem, p.110). Entre seus feitos está a introdução da raça charolesa no Paraná (Ibidem, p.90-104). Manoel foi casado por 65 anos com Maria da Luz

\footnotetext{
${ }^{3}$ Manoel Lustosa Martins (1892-1983) era filho de Fermino Martins dos Santos e Balbina Lustoza Martins (Dona Sinhara); avós paternos: Bento dos Santos Martins e Anna Pereira da Luz; avós maternos: Domingos Lustoza de Siqueira e Dulce Gregória de Souza; era irmão de Crescêncio; Manoel Lustosa Martins casou com Maria da Luz Carneiro Pacheco, filha de Sansão Antonio Carneiro e Maria do Belém Pacheco Carneiro (MARTINS, 1992).
} 
Carneiro Pacheco (data do casamento, 15/06/1918); ela era, também, de importantes famílias desbravadoras dos Campos de Palmas. Os sogros eram Sansão Antonio Carneiro (ex-prefeito de Clevelândia) e Maria do Belém Pacheco Carneiro. Manoel e Maria da Luz eram primos distantes (Ibidem, p.87). Manoel e Maria tiveram cinco filhos: Jupira, Jacira, Firmino, Alaor Prata e Juarez. Jupira e Jacira casaram com futuros políticos, como se verá a seguir. Firmino, falecido com apenas 27 anos, agrônomo, casou com Alice Rocha Loures. Alaor Prata Martins, engenheiro, casou com Maria (Regina) de Moraes. Juarez Martins, fazendeiro e pecuarista, casou com Carmella Domingas Bevilacqua (Ibidem, p.130).

\begin{abstract}
Dessas uniões nasceram dezesseis netos. Dezessete com Marco Antônio, filho do primeiro casamento de Maria de Moraes e que ocupa atualmente o cargo de Juiz de Direito Titular da 3a Vara Cível de Curitiba. Destacam-se na área política Antônio Martins Annibelli, Deputado Estadual; Cândido Manoel Martins de Oliveira, Conselheiro do Tribunal de Contas do Estado e Luiz Alberto Martins Oliveira, suplente de Senador.

No segmento agropecuário, Manoel Lustosa Martins Neto, Presidente da Associação Paranaense de Criadores de Charolês - AprCC - e da Comissão de Exposições do Paraná COMEXPA (MARTINS, 1992, p.130-131).
\end{abstract}

A filha Jacira casa com Antônio Anibelli, que entrou para famílias tradicionais e de grande influência política e econômica do Sudoeste do Paraná, como as famílias Lustosa Martins, Carneiro e Pacheco. A partir daí a família Anibelli foi inserida na política paranaense, portanto, seus 72 anos de vida pública parlamentar podem ser aumentados pelo de seu sogro e familiares Lustosa e Carneiro.

Manoel Lustosa Martins também foi prefeito de Clevelândia (1930 a 1936) e militou no PTB (Partido Trabalhista Brasileiro) de Getúlio Vargas. Era amigo do governador/interventor Manoel Ribas, e do próprio Getúlio Vargas. Prefeito que realizou inúmeras obras; político de destaque e influente na região.

A outra filha de Manoel, Jupira casou com Cândido Machado de Oliveira, que foi deputado pelo PSD (Partido Social Democrático), nas legislaturas de 1951-54, 1955-58 e 1959-63. Dessa família tem-se Luis Alberto Martins de Oliveira, deputado e Senador pelo Paraná4 ${ }^{\text {, bem como }}$ Cândido Manoel Martins de Oliveira, deputado estadual entre 1971-75, e secretário de Educação e

\footnotetext{
${ }^{4}$ Senador Luís Alberto de Oliveira. Disponível em: https://www25.senado.leg.br/web/senadores/senador/-/perfil/56. Acesso em 26 de abril de 2017.
} 
Segurança Pública em diferentes governos ${ }^{5}$. Na década de 1950, também, Antônio Anibelli, seu genro, foi deputado estadual pelo PTB, que também continuou na política. Os dois genros eram advogados e promotores de justiça e estavam em partidos políticos opostos. Nessa mesma década, Manoel retorna como vereador em Clevelândia, e continua sempre participativo nos acontecimentos políticos e públicos na região (MARTINS, 1992, p.119-129).

Enfim, essa conexão com a família Lustosa por parte de Anibelli foi fundamental para a sua ascensão política e com reflexos em sua futura geração, que permanece no poder até hoje.

\section{BIOGRAFIAS DOS ANNIBELLE - POLÍTICOS}

\section{Antônio Annibelli: (Pai) ${ }^{6}$}

A família Annibelli começou a trajetória política com patriarca Antônio Annibeli, nascido em São Paulo em 14 de outubro de 1911, filho de Alberto Annibelli e de Francisca Annibelli. Aos seis meses de idade, seus pais mudam-se para o Rio Grande do Sul, município de Santa Maria da Boca do Monte onde estuda até o 4ㅇano, depois se muda para Curitiba, onde concluiu os estudos básicos em 1931. Como se percebe, Annibelli pai teve a oportunidade de estudar, o que na época era algo incomum.

Na revolução de 1930, Antônio Annibelli inscreve-se nas forças revolucionárias a favor de Getúlio Vargas. "Eu sou revolucionário de 1930", diz ele, pertencendo à instituição patriótica 5 de outubro, com sede no centro de Curitiba.

Depois, entrou na Faculdade de Direito da Universidade do Paraná formando-se em 19 de dezembro de 1936. Lembrando que era uma faculdade particular. Anibelli, porém, disse que era "estudante pobre". Ainda quando acadêmico, começou a trabalhar como funcionário adjunto do

\footnotetext{
5 Assembleia Legislativa presta homenagem a Ex-deputados do Sudoeste durante Interiorização. Disponível em: http://www.alep.pr.gov.br/sala_de_imprensa/noticias/assembleia-legislativa-presta-homenagem-a-ex-deputados-dosudoeste-durante-interiorizacao-1. Acesso em 26 de abril de 2017.

${ }^{6}$ A presente descrição da biografia de Antônio Annibelli (pai) é retirada do livro Governadores do Paraná, na qual o próprio Annibelli relata um pouco de sua vida aos entrevistadores SEBASTIANI e FARIA (1997).
} 
promotor público. Ao ser aprovado no concurso público para a Capital Federal, foi nomeado pelo então presidente Getúlio Vargas, para o cargo de promotor público federal sendo designado pela comarca de Ipiranga, e depois, no município de Clevelândia, aonde chegou em março de 1937. De acordo com Annibelli, ele foi promovido ao pedido do Interventor Manoel Ribas, provavelmente padrinho político de Annibelli, junto com o seu sogro, Manoel Lustosa Martins.

Antonio Annibelli casou, então, com Jacira Martins Annibelli, que era filha da importante família Lustosa Martins e Carneiro no Paraná. Jacira é filha de Manoel Lustosa Martins e Maria Luiz Carneiro Martins $\quad$ (Fonte: $\quad$ https://www.geni.com/people/Jacira-MartinsANNIBELLI/6000000010887904527. Acesso em 05/04/2017).

Logo, torna-se prefeito de Clevelândia, em 1944, dando continuidade aos trabalhos políticos de seu sogro Manoel e iniciando desta forma a sua carreira política. De prefeito, candidata-se a deputado estadual, elegendo-se em 1950.

Tinha o importante cargo de Promotor Público Federal. Exercendo o cargo de prefeito e depois, ao mesmo tempo, o mandato de Deputado Estadual e chegou a Presidente da Assembleia Legislativa, em 1952. Era do PTB (Partido Trabalhista Brasileiro - da linha de Getúlio Vargas). Annibelli detinha o poder político e jurídico, ao mesmo tempo.

Reelegeu-se deputado estadual em 1954 e 1958. Em 1955 foi novamente presidente da Assembleia Legislativa do Paraná, porém, agora substituiu o governador Bento Munhoz da Rocha Neto que renunciou ao governo do Estado para ser candidato a Vice-Presidente de Café Filho, mas barrado por Carlos Lacerda, Munhoz da Rocha ocupou, então, o cargo de Ministro da Agricultura no governo de Café Filho. Antonio Annibelli governou o Paraná de 3 de abril a 1 de maio de 1955, logo em seguida transmitiu o cargo ao novo governador, Adolpho Oliveira Franco, eleito pela Assembleia Legislativa. Portanto, outro personagem importante de sua rede política foi o governador Bento Munhoz da Rocha Neto, que ele chama de amigo.

Em 1962 foi eleito Deputado Federal pelo mesmo partido. Em 1965 ingressou no MDB, sendo reeleito em 1966. Em 1970, candidato a nova reeleição, ficou como primeiro suplente, assumindo o mandato novamente em 1973. Antes de terminar seu mandato, 1974 apresenta o filho Antônio Martins Annibelli para substituí-lo. Foi um dos fundadores do MDB do Paraná (SEBASTIANI \& FARIA, 1997). 
Como visto, a rede de Annibelli foi sendo ampliada, do sogro Manoel Lustosa Martins, temse igualmente a importância do interventor do Paraná, Manoel Ribas, do presidente da República, Getúlio Vargas e depois, na redemocratização de 1945, do governador do Paraná, Bento Munhoz da Rocha Neto.

\section{Antônio Martins Anibelli: (Filho) ${ }^{7}$}

Antônio Martins Anibelli, filho do ex-deputado federal Antônio Anibelli e Jacira Martins Anibelli (família Lustosa Martins e Carneiro), nasceu em Clevelândia (PR) no dia 14 de novembro de 1943. Formou-se em Direito pela Faculdade de Direito de Curitiba em 1968, seguindo o mesmo curso do pai. Desde cedo, quando ainda era jovem ingressou no quadro de funcionários da Secretaria da Assembléia Legislativa do Paraná como oficial Legislativo, provavelmente por influência do pai, o colocando para trabalhar em cargos públicos.

Foi deputado federal em 1974 pelo MDB onde exerceu o cargo de vice-presidente da Comissão de Agricultura e Política Rural. Foi reeleito deputado federal, em 1978, novamente pelo MDB. Em 1982, candidatou-se a deputado estadual sendo reeleito, sucessivamente, em 1986, 1990, 1994, 1998. Foi, também, como seu pai, um dos fundadores do MDB no Paraná.

Casado com Yara Maria Baggio Anibelli, de uma tradicional família italiana que chegou em Curitiba no ano de 1879 no bairro Água Verde, no início da colonização italiana, e que hoje possuí um dos maiores Grupos de empresas brasileiras no ramo imobiliário e de construções, que teve início em 1948, quando o fundador Holier Baggio, construía casas no interior do Paraná. Em 1981, Edemarques e José Américo Baggio, fundaram a primeira Construtora do grupo, que tinha como foco a incorporação de edifícios residenciais.

Da união de Antônio Martins Annibelli e Yara Baggio Anibelli vieram quatro filhos: Isabella, Mariana, André e o deputado Antônio Anibelli Neto.

\footnotetext{
7 A presente biografia tem como referência os sites da Câmara dos Deputados Federais e da Câmara dos Deputados Estaduais do Paraná. Disponível em: http://www.alep.pr.gov.br/deputados/perfil/108-antoniomartins-anibelli. Acesso em 25/04/2017.
} 
Antônio Anibelli Neto: (Neto) ${ }^{8}$

Antonio Anibelli Neto, nascido em Curitiba em 18 de setembro de 1973 . Foi eleito pela primeira vez deputado estadual em 2010 conquistando votos em 184 municípios paranaenses. Em 2014 foi reeleito pela segunda vez com 49.349 votos.

Começou a trajetória política na faculdade. Graduado em Medicina Veterinária e cursando faculdade de Direito, em 1999, foi vice-presidente e presidente do Centro Acadêmico. Em 2001 foi eleito vice-presidente da União Paranaense dos Estudantes (UPE) e presidente da mesma entidade em 2002 e 2003.

Em 2003 foi eleito, vice-presidente da união Nacional dos Estudantes (UNE) no Paraná. Logo em seguida, ocupou a Secretaria Geral e a presidência do PMDB Jovem.

Em 2007, assumiu o Departamento Rodoviário aos Municípios da Secretaria de Estado dos Transportes. Assim como o pai, inicia sua carreira em cargos públicos.

Carregando o nome do pai, Antônio Martins Anibelli, que foi Deputado Estadual e Federal por nove mandatos, chegando à presidência da Assembléia Legislativa, e do avô, Antônio Anibelli, que foi Deputado Estadual e Federal por seis mandatos e chegou a ser governador do Estado, Anibelli Neto já está no segundo mandato como deputado estadual, dando continuidade ao ciclo da genealogia política da família Anibelli que está no poder a 72 anos.

Portanto, o deputado Annibelli Neto, representa a atual geração de famílias que se inserem na história política do Paraná desde o período colonial demonstrada pela genealogia de seus membros. Essas famílias atuam junto ao poder no Estado por meio das redes e conexões entre si e que crescem cada vez mais, transformando a política em um negócio de família. Desta forma, o deputado Annibelli Neto, representa a atual geração de famílias que continuam a fazer parte da história política do Paraná há muito tempo.

\footnotetext{
8 A presente biografia tem como referência o site da Assembleia Legislativa do Paraná. Disponível em: http://www.alep.pr.gov.br/deputados/perfil/18-anibelli-neto. Acesso em 25/04/2017. E, no site pessoal. Disponível em: www.anibelli.com.br/biografia. Acesso em 25/04/2017.
} 


\section{CONSIDERAÇÕES FINAIS}

Diante das pesquisas difundidas nesse trabalho, é possível afirmar que o Brasil desde sua origem foi construído por meio das relações e conexões familiares. As oligarquias no Brasil foram sendo lapidadas desde a época colonial e no Paraná este fenômeno ocorre com maior intensidade a partir de sua emancipação política há 153 anos. Desta forma não há novidade em ressaltar que no Paraná uma rede de interesses comandada pela classe dominante mantém e reproduz seu poder e privilégios ao longo das gerações. E segundo relata Ricardo Oliveira em seu livro "Teia do Nepotismo":

O Brasil construiu a sua própria nobreza e esta construiu o Brasil colonial tal como o conhecemos. A elite colonial, a classe dominante colonial, é uma grande rede social e política de famílias viabilizadas por longas genealogias de poder.

Com a construção dessa estrutura de poder baseada nos relacionamentos de poder social, político e econômico entre as famílias da nobreza, surge o termo nepotismo que segundo Oliveira:

É uma relação social e política plasmada em ambientes institucionais pré-modernos assolados pela patronagem e pelo clientelismo. O nepotismo é uma rede social e política de grupos sociais e famílias para obtenção e preservação do poder político e a dominação da elite.

Diante do cenário apresentado na política paranaense, compreendemos que essas conexões políticas e econômicas entre os atores ocorrem de forma bastante acentuada a partir daquilo que denominamos de nepotismo, isto é, famílias históricas e emergentes que constroem redes de interesses recíprocos que permeiam a sociedade e a política paranaense. Segundo Oliveira (2012, p.54):

As conexões entre genealogias tradicionais e instituições políticas (poderes Executivo, Legislativos, Judiciário, empresas estatais, tribunais de contas, cartórios e tabelionatos), quase nunca investigadas sob o prisma do nepotismo, passam a ganhar novos sentidos e referenciais dentro de amplas redes sociais e políticas de nepotismo e parentesco. A relação envolvente entre as esferas pública e privada também é uma relação de conexões pessoais. Relações preferenciais com empresas privadas fornecedores de bens e serviços para o Estado, em função de estruturas de parentesco. 
Desta forma, Oliveira constata que a política é muito vantajosa para estas famílias por que:

\begin{abstract}
Os partidos políticos se enfraquecem ou desaparecem como instituições e a política se resume aos negócios de famílias, com seus interesses e redes de dependências pessoais. Estados como o Paraná e os estados nordestinos têm longas histórias políticas de oligarquias familiares atuantes nas últimas décadas. O familismo ainda é constante na política brasileira.
\end{abstract}

Quando utilizamos classe dominante é possível ressaltar que um grupo de pessoas na sociedade tomou posse dos mais variados dispositivos do poder. Segundo Faoro $(2001$, p.823):

\begin{abstract}
O domínio tradicional se configura patrimonialismo, quando aparece o estado-maior de comando do chefe junto à casa real, que se estende sobre o largo território subordinando muitas unidades políticas. Num estágio inicial o domínio patrimonial desta forma constituído pelo estamento apropria as oportunidades econômicas de desfrute dos bens, das concessões, dos cargos, numa confusão entre o setor público e privado que, com aperfeiçoamento da estrutura, se extrema em competências fixas, com divisão de poderes, separando-se o setor fiscal do setor pessoal.
\end{abstract}

De certa forma, parece que ainda não se conseguiu superar o regime patrimonialista no Brasil, em que a família tornar-se um elemento importante na conquista do poder público, mesmo sendo ele de caráter democrática, em que vários candidatos apresentam seu nome para serem os eleitos representantes de uma determinada população. Mas, acabam vencendo membros de famílias que já possuem determinada experiência na política, as vezes por gerações.

\title{
REFERÊNCIAS
}

ANNIBELLI, Baggio Mariana. (2009). Contestado: Um Território Socioambiental. Curitiba: PUC. Dissertação apresentada ao Programa de Pós-Graduação, Pesquisa e Extensão em Direito da Pontifícia Universidade Católica do Paraná, Curitiba.

MARTINS, Nadia Bevilaqua. (1992). Manoel Lustosa Martins: a história de um pioneiro. Curitiba: Editel.

NICOLAS, Maria. (1984). 130 anos de vida parlamentar paranaense. Curitiba: Assembleia Legislativa do Paraná. 
SEBASTIANI, Sylvio \& FARIA, Enéas. (1997). Governadores do Paraná. “A história por quem construiu a história". Curitiba: Sistani.

OLIVEIRA, Ricardo Costa de. (2001). O silêncio dos vencedores: genealogia, classe dominante e Estado no Paraná. Curitiba: Moinho do Verbo.

OLIVEIRA, Ricardo Costa de. (2012). Na teia do nepotismo. Curitiba: Insight.

FAORO, Raimundo. (1976). Os donos do poder. Rio de Janeiro, Globo.

Sites:

Biografia de Antônio Annibelli: http://www.fgv.br/cpdoc/acervo/dicionarios/verbetebiografico/annibelli-antonio-pai. Acesso em 26/04/2017.

www.gazetadopovo.com.br/construindo-uma-historia Acesso em 26/04/2017.

www.immigrazioneveneta.blogspot. Acesso em 26/04/2017. 